\title{
O FINANCIAMENTO DO ENSINO SUPERIOR
}

\author{
Elisa Wolynec $(1)$
}

\begin{abstract}
RESUMO: Neste trabalho, são discutidos os itens básicos da composição orçamentária de universidades e, em especial, a relação que deveria haver entre as despesas de pessoal $e$ custeio. São apresentados dados orcamentários referentes ao financimento do ensino superior em paises europeus, e outros indicadores relevantes. Comparaçoes entre esses indicadores são feitas para as universidades do Estado de São Paulo e para o Sistema Fe. deral de Ensino Superior.
\end{abstract}

ABSTRACT: The major itens in the composition of universities budget are discussed in this work, especially the relationship between recurrent expenditure and personnel. Budget data and other related indicators from Higher Education in european countries are presented. Comparisions are made with São Paulo State Universities and the Federal System of Higher Education.

\section{Introdução}

A dotação orçamentária das universidades pode ser subdividida em quatro itens principais:
a) Pessoal - despesas com o pagamento dos salários dos do- centes e das equipes técnicas e administrativas de apoio.
b) Custeio - despesas de manutenção das atividades de ensi- no, como por exemplo, material didático, produ- tos químicos para os laboratórios didáticos, ma- nutenção dos prédios, conserto e substituição de equipamentos dos laboratórios didáticos, despe- sas de manutenção dos biotérios, assinatura de periódicos, aquisição de livros etc.
c) Capital - despesa de expansão, incluindo-se construção de edifícios, compra de equipamentos técnico-cien- tíficos etc.
d) Pesquisa - verbas destinadas ao desenvolvimento de pesqui- sas.

Nas universidades públicas, as verbas de pessoal e custeio são

(1) Professora Adjunta no Instituto de Física da USP, Coordenadora de Administração Geral da USP 
anualmente fornecidas pelo Estado e, de acordo com os padrões internacionais, essas verbas devem ser de magnitude tal que:

$$
\epsilon=\frac{\text { verba para custeio }}{\text { verba de pessoal }+ \text { verba de custeio }} \cong 0,3
$$

ou seja, a dotação anual para custeio deve ser, pelo menos, 30\% da verba de pessoal mais custeio.

O item Capital é variável, ocorrendo quando há necessidade de expansão e a dotação pode vir do Estado ou de agências financiadoras. Finalmente, o item Pesquisa é provido através de projetos de pesquisa específicos, incluindo-se, como fontes de financiamento, o próprio Estado através de agências financiadoras de pesquisa, bem como a indústria. Essa é uma forma de a sociedade estabelecer prioridades para os projetos de pesquisa, podendo financiar as que levem a desenvolvimentos de seu interesse.

\section{Dados do Sistema de Ensino Superior Europeu}

O sistema europeu foi escolhido para comparação por ser o mais próximo do vigente em nosso país. Nos Estados Unidos, a maioria das universidades de alto padrão são particulares e as taxas anuais pagas pelos alunos estão na faixa de US $\$ 10,000$ - 15,000 (MIT, Princeton, por exemplo), as quais são suficientes para cobrir as despesas de pessoal e custeio. Para comparação, um aluno na USP custa em torno de US $\$ 4,000$.

O sistema europeu é em sua maioria público e, quando taxas são cobradas dos alunos, estas cobrem $1-2 \%$ dos custos totais, podendo ser desprezadas na análise do financiamento fornecido pelo Estado. Os dados referentes ao sistema europeu, utilizados neste trabalho, foram obtidos da CRE (1987)(1). A Tabela 1 mostra o fator $\epsilon$ para dezesseis paises europeus. Nessa tabela, o período refere-se aos anos em que os dados orçamentários estavam disponíveis. Nesses casos, o fator $\epsilon$ que aparece na Tabela 1 refere-se a uma média sobre os anos indicados. Para alguns países, os dados referem-se exclusivamente à dotação orçamentária das universidades e, nos demais casos, referemse ao financiamento do ensino superior ( $N a$ Europa há, aproximadamente 300 universidades e 3 mil instituições de ensino superior). Como mostra a Tabela 1, o valor médio de $\epsilon$ é 30\%, considerando-se todo o sistema de ensino superior, o qual contém, na maioria dos casos, um grande número de escolas profissionalizantes que não reque-

(1) Conferência de Reitores das Universidades Européias (CRE) - CRE-INFORMATION n. 77 e 79, 1987. 
rem aulas laboratoriais para formação de seus alunos. Se considerarmos apenas as universidades verifica-se que, para os 8 paises constantes da Tabela 1, em nenhum caso $\epsilon$ é menor do que $30 \%$ e a média de $\epsilon$ para esses países é $34,6 \%$.

TABELA 1. Financiamento do ensino superior em paises europeus em termos do fator $\epsilon=$ custeio/(pessoal + custeio).

\begin{tabular}{l|c|c|c}
\hline Pais & $\epsilon(\%)$ & Período & Item orçamentário \\
\hline \hline Alemanha & 26,5 & $75-83$ & Educação Superior \\
Austria & 39,6 & $75-85$ & Educação Superior \\
Dinamarca & 31,7 & $83-85$ & Universidades \\
Espanha & 18,2 & $75-85$ & Educação Superior \\
Finlândia & 32,2 & $75-85$ & Universidades \\
França & 14,8 & 82 & Educação Superior \\
Grécia & 19,0 & $75-86$ & Educação Superior \\
Holanda & 40,7 & $76-83$ & Universidades \\
Irlanda & 30,0 & $84-85$ & Universidades \\
Itália & 36,7 & $75-81$ & Universidades \\
Noruega & 40,0 & $85-86$ & Educação Superior \\
Polônia & 28,7 & $79-84$ & Educação Superior \\
Reino Unido & 33,0 & $75-83$ & Universidades \\
Suécia & 20 & $84-85$ & Educação Superior \\
Suíca & 40,5 & $75-84$ & Universidades \\
Turquia & 32,2 & $83-86$ & Universidades \\
\hline
\end{tabular}

Média Geral $\epsilon=30,2$

Média de $\epsilon$ para universidades: $\epsilon=34,6$

OBS.: Despesas de Capital foram excluidas no cálculo de $\epsilon$.

Há suficientes evidências, portanto, para considerarmos como necessário, para o financiamento adequado de uma universidade o valor de $\epsilon=30 \%$. Entretanto, a adoção desse parâmetro implica que outros indicadores relevantes sejam considerados, em especial o aporte de pessoal em relação ao número de alunos. A Tabela 2 mostra, para vários países europeus o número de alunos e docentes, a razão entre estes, bem como o ano a que se referem os dados(1). A razão média, considerando-se todos os países, é 14,9 alunos/docentes.

(1) Conferéncia de Reitores das Universidades Européias (CRE) - CRE-INFORMATION n: 77 e 79, 1987. 
TABELA 2. Número de alunos e docentes em sistemas universitários de paises da Europa.

\begin{tabular}{l|c|c|c|c}
\hline País & No alunos & No docentes & Aluno/docente & Ano \\
\hline \hline Alemanha & 996820 & 75761 & 13,5 & 83 \\
Áustria & 162837 & 13385 & 12,2 & 84 \\
Bélgica & 111871 & - & - & 84 \\
Dinamarca & 88636 & 5929 & 14,9 & 85 \\
Espanha & 670639 & 40062 & 16,7 & 83 \\
Finlândia & 90400 & 6940 & 13,0 & 85 \\
França (*) & 968484 & 40881 & 23,6 & 85 \\
Grécia & 95806 & 6482 & 14,8 & 79 \\
Holanda & 166802 & 17975 & 9,3 & 83 \\
Irlanda & 25250 & 1862 & 13,6 & 83 \\
Itália (*) & 1322982 & 43501 & 28,3 & 85 \\
lugoslávia (*) & 267891 & 11444 & 25,2 & 85 \\
Noruega & 39827 & 4567 & 8,7 & 81 \\
Polônia & 111371 & - & - & 85 \\
Portugal & 83516 & 8006 & 10,4 & 82 \\
Reino Unido & 338907 & 44192 & 7,7 & 83 \\
Suécia & 108145 & 9784 & 11,0 & 84 \\
Suíça & 72604 & 5980 & 12,1 & 85 \\
Turquia & 25011 & 449414 & 17,9 & 86 \\
\hline Valores málios & & & &
\end{tabular}

Valores médios e respectivo desvio padrão

Todos: Razão al uno docente $=14,9 \pm 5,9$

(*) Excluindo: Razão aluno/docente $=12,5 \pm 3,0$

Algumas considerações adicionais devem ser feitas. A França, I tália e lugoslávia não possuem processo de seleção para ingresso na universidade, admitindo um grande número de estudantes que são, posteriormente, selecionados no decorrer dos dois primeiros anos. Nessa fase é feito um ensino de massa com classes de até 400 alunos. Excluindo-se esses países, para o cálculo da razão média, obtém-se 12,5 alunos/docente. Há ainda uma ressalva a ser feita. Atualmente, $50 \%$, ou um pouco mais, dos alunos matriculados nas universidades européias estão na área das Humanidades, de forma que a razão aluno/docente não é diretamente comparável à situação de nosso país. 
A Tabela 3 mostra a razão aluno/docente para as diferentes áreas, nos casos em que estes dados estão disponíveis. A razão média é 26 alunos/docente nas Humanidades e 10,6 para Medicina, Ciências e Engenharia. Pode-se concluir que em termos gerais, a razão aluno/docente não deve ser inferior a 10 alunos/docente.

TABELA 3. Razão (aluno/docente) em universidades européias, nas diferentes áreas.

\begin{tabular}{|c|c|c|c|c|c|}
\hline Pais & Ano & Humanidades & Ciências & $\begin{array}{l}\text { Engenharia/ } \\
\text { Tecnologia }\end{array}$ & Medicina \\
\hline Alemanha & 83 & 23,1 & 9,9 & 11,3 & 5,0 \\
\hline Áustria & 84 & 19,1 & 6,9 & 8,2 & 9,7 \\
\hline Bélgica & 84 & - & - & - & - \\
\hline Dinamarca & 85 & 21,2 & 8,7 & 7,8 & 5,6 \\
\hline Espanha & 83 & 26,7 & 10,4 & 11,3 & 10,7 \\
\hline Finlândia & 85 & - & - & - & - \\
\hline França & 85 & - & - & - & - \\
\hline Grécia & 79 & 38,7 & 7,8 & 8,0 & 7,0 \\
\hline Holanda & 83 & - & - & - & - \\
\hline Irlanda & 83 & - & - & - & - \\
\hline Itália & 85 & 48,0 & 16,4 & 30 & 13,4 \\
\hline lugoslávia & 85 & 41,7 & 16,4 & 18,2 & 17,9 \\
\hline Noruega & 81 & - & - & - & - \\
\hline Polônia & 81 & - & - & - & - \\
\hline Portugal & 82 & 30 & 9,8 & 6,6 & 6,6 \\
\hline Reino Unido & 83 & 10,7 & 6,4 & 7,7 & 4,2 \\
\hline Suécia & 84 & 12,9 & 7,8 & 7,8 & 12,0 \\
\hline Suíça & 85 & 14,7 & 7,3 & 23,5 & 9,5 \\
\hline Turquia & 86 & - & - & - & - \\
\hline
\end{tabular}

Valor médio para Medicina, Ciências e Engenharia: 10,6 
A Figura 1 mostra o fator $\epsilon$ no orçamento da USP nos últimos 12 anos, e a Figura 2 mostra esse fator para as IES federais no periodo 70 - 86. Em ambos os casos o fator $\epsilon$, nos últimos anos, está bem aquém do mínimo necessário. Seria conveniente que fosse fixado um valor mínimo para $\epsilon$, que poderia até ser $20 \%$, impedindo-se flutuações decorrentes da política governamental, uma vez que estas se refletem negativamente na qualidade do ensino.

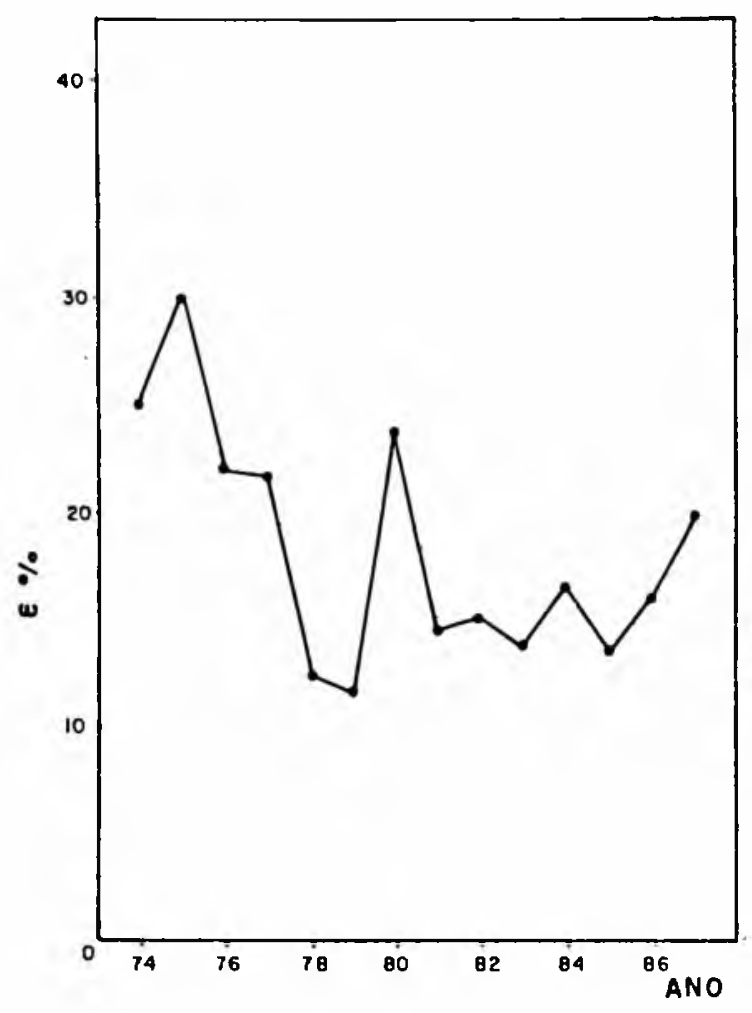

Figura 1. Evolução do orçamento da USP em termos do fator $\epsilon$.

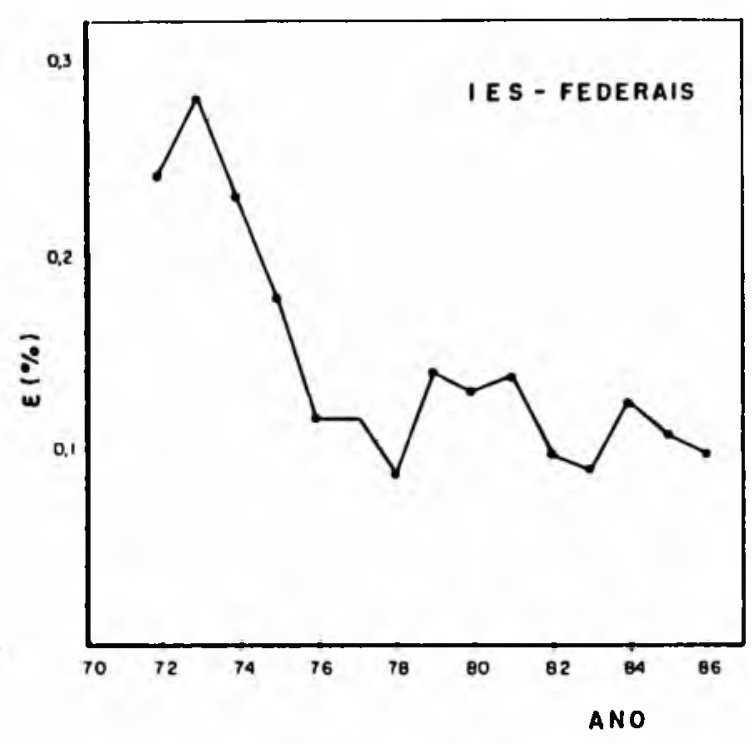

Figura 2. Evolução do orçamento das IES federais em termos do fator $\epsilon$.

A Tabela 4 mostra o fator $\epsilon$ para as universidades do Estado de São Paulo e para as IES federais, no período $85-86$. Para o ano de 1985 , os valores em cruzeiros foram divididos por mil para reversão em cruzados, tendo apenas sentido comparativo. Custeio está sendo considerado como sendo a soma de Despesas Correntes, menos Pessoal e Reflexos, mais despesas de Capital menos Obras.

A Tabela 4 mostra, também, o custo aluno para o ano de 1986. Deve-se salientar que esse custo aluno é obtido dividindo-se, simplesmente, a dotação do Estado, ou do MEC, pelo número de alunos. Esse custo não pode ser comparado ao de instituições particulares que não fazem pesquisa e não possuem a maioria dos docentes em tempo 
integral. Para citar a USP como exemplo, na dotação do Estado utilizada no cálculo do custo aluno estão incluídos sete museus e dois hospitais que prestam serviços à população.

TABELA 4. Pazło = Custeio/(Pessoal + Custeio $)$ E Custo Aluno

\begin{tabular}{l|c|c|c|c|c|c}
\hline \hline UNIVERSIDADE & ANO & $\begin{array}{c}\text { PESSOAL } \\
\text { CzS }\end{array}$ & $\begin{array}{c}\text { CUSTEIO } \\
\text { Cz\$ }\end{array}$ & $\%$ & $\begin{array}{c}\text { No DE } \\
\text { ALUNOS }\end{array}$ & $\begin{array}{c}\text { CUSTO ALUNO } \\
\text { C2\$ }\end{array}$ \\
\hline UNESP & 1985 & 292.886 .195 & 68.002 .831 & 18.84 & - & - \\
\hline \multirow{2}{*}{ UNICAMP } & 1986 & 881.674 .704 & 251.453 .912 & 22.19 & 15.697 & 72.187 \\
\hline USP & 1985 & 265.497 .948 & 154.152 .324 & 36,73 & - & - \\
\hline IES FEDERAIS & 1986 & 952.872 .316 & 514.898 .008 & 35,08 & 13.862 & 105.884 \\
\hline
\end{tabular}

E importante, comparar-se, também, os outros indicadores pertinentes. A Tabela 5 mostra a evolução do número de docentes, funcionários e alunos nas IES federais e a Tabela 6 mostra as razões alunos/docente e alunos/funcionário para as universidades do Estado de São Paulo e IES federais. Em princípio, seria possível, na maioria das universidades, ampliar-se as vagas em $50 \%$ sem necessidade de um acréscimo correspondente em termos de docentes e funcionários.

TABE LA 5. IES FEDERAIS - Número de docentes, funcionários e alunos.

\begin{tabular}{l|l|c|c|c|c}
\hline ANO & DOCENTES & $\begin{array}{c}\text { FUNCIONÁRIOS } \\
\text { DE APOIO }\end{array}$ & $\begin{array}{c}\text { ALUNOS } \\
\text { FUNCIONÁRIO }\end{array}$ & ALUNOS & $\begin{array}{c}\text { ALUNOS/ } \\
\text { DOCENTE }\end{array}$ \\
\hline 1980 & 44.123 & 65.016 & 5.14 & 334717 & 7.58 \\
1984 & 46.321 & 80.887 & 4.51 & 364921 & 7,87 \\
1986 & 55.057 & 100.637 & 3.44 & 364171 & 6.61 \\
\hline
\end{tabular}

Fonte: Dados fornecidos pelo MEC

TABELA 6. Razāo Aluno/Docente e Aluno/Funcionário

\begin{tabular}{l|c|c|c|c|c}
\hline UNIVERSIDADE & $\begin{array}{c}\text { No DE } \\
\text { ALUNOS }\end{array}$ & $\begin{array}{c}\text { NO DE } \\
\text { DOCENTES }\end{array}$ & $\begin{array}{c}\text { NO DE } \\
\text { FUNCIONARIOS }\end{array}$ & $\frac{\text { ALUNOS }}{\text { DOCENTE }}$ & FUNCIONARIO \\
\hline \hline UNESP & 15.697 & 2.508 & 5.651 & 6,26 & 2,78 \\
\hline UNICAMP & 13.862 & 1.894 & 8.924 & 7,32 & 1,55 \\
\hline USP & 49.278 & 4.936 & 12.890 & 9,98 & 3.82 \\
\hline IES FEDERAIS & 364.171 & 55.057 & 100.637 & 6,61 & 3.62 \\
\hline
\end{tabular}

Os dados referem-se ao ano de 1986 
Foram apresentados indicadores referentes à dotação orçamentária de universidades, baseados no sistema europeu de ensino superior. Os principais indicadores são o fator $\epsilon$ que relaciona despesas de custeio e pessoal e a relação entre alunos e docentes.

Uma análise desses indicadores para universidades públicas do País mostra oscilações de $\epsilon$ ao longo do tempo e variações consideráveis de uma para outra universidade. A razão aluno/docente está, em geral, abaixo do desejável. As diferenças na razão aluno/docente e no fator $\epsilon$ mostram a necessidade de estabelecer-se uma política para a dotação orçamentária das universidades, que Ihes permita um planejamento de longo prazo, independente das flutuações decorrentes das preferências ou políticas dos dirigentes governamentais. Seria conveniente fixar um valor mínimo para a razão aluno/docente, levando-se em conta a peculiaridade de cada universidade. Um valor de $\epsilon=0,3$ permitiria às universidades, inclusive, o desenvolvimento de pesquisas que ainda não fossem de porte suficiente para justificar financiamentos específicos através de projetos submetidos aos órgãos financiadores.

\section{A EMENDA CALMON E O PROBLEMA DO FINANCIAMENTO DO ENSINO SUPERIOR NO SISTEMA FEDERAL}

A parcela destinada à União para manutenção e desenvolvimento do ensino, em decorrência da Emenda Calmon é de $13 \%$ da receita tributária menos o montante transferido a estados e municípios, decorrente de preceito constitucional. A Tabela 7 mostra o que a União estima arrecadar em 1987 perfazendo um total de 591 bilhões de cruzados, dos quais 306 bilhões constituem a receita tributária.

TABELA 7. Resumo Geral da Receita - 1987

\begin{tabular}{|c|c|}
\hline Receitas & $\left(C_{2} \$\right)$ \\
\hline 1. RECEITAS CORRENTES & $437.287 .897 .000,00$ \\
\hline Receita Tributária & $306.000 .000 .000,00$ \\
\hline 1. 2 Demais Receitas & $131.287 .897 .000,00$ \\
\hline 2. RECEITAS DE CAPITAL & $154.557 .103 .000,00$ \\
\hline TOTAL & $591.845 .000 .000,00$ \\
\hline
\end{tabular}


Deve-se salientar que esta estimativa foi efetuada com previsão de inflação nula. Pode-se, portanto, discutir o montante destinado ao ensino superior em termos de preços de 1986. O montante, destinado à União para o ensino, em decorrência da Emenda Calmon, é de $\sim 28$ bilhões e está discriminado na Tabela 8. Desse montante cabem ao MEC 25 bilhões.

TABELA 8. Distribuição dos Recursos para Manutenção e

Desenvolvimento do Ensino - 1987 (Emenda Constitucional No 24, de 01/12/83)

\begin{tabular}{|c|c|}
\hline ÓRGĀOS & $\left(C_{2} \$\right)$ \\
\hline Ministério da Aeronáutica & $79.314 .000,00$ \\
\hline Ministério da Agricultura & $93.268 .000,00$ \\
\hline Ministério da Educação & $24.911 .940 .000,00$ \\
\hline Ministério do Exército & $298.610 .000,00$ \\
\hline Ministério da Saúde & $39.701 .000,00$ \\
\hline Ministério das Ciências e Tecnologia & $442.000 .000,00$ \\
\hline $\begin{array}{l}\text { Transferência a Estados, Distrito Federal e } \\
\text { Municipios }\end{array}$ & $2.125 .094 .000,00$ \\
\hline TOTAL & $27.989 .927 .000,00$ \\
\hline
\end{tabular}

Em 1986 o MEC gastou com o ensino superior, conforme a Tabela 9, $\sim 17$ bilhões, dos quais $\sim 16$ bilhões foram para pagamento de pessoal. Portanto, $69 \%$ do orçamento do MEC provenientes da Emenda Calmon foram gastos com o sistema federal de ensino superior. A Tabela 10 mostra os auxílios e financiamentos (Programa Nova Universidade) concedidos às instituições de ensino superior não-federais e a fonte desses recursos.

TABELA 9. Gastos do MEC com o Ensino Superior do Sistema Federal - 1986

\begin{tabular}{|c|c|}
\hline ELEMENTOS & $\left(C_{2} \$\right)$ \\
\hline Pessoal & 15.260 .216 .600 \\
\hline Outros Custeios e Capital & 1.423.255.573 \\
\hline Equipamento & 174.691 .912 \\
\hline Obraș & 199.658 .480 \\
\hline Amortização & 13.076 .770 \\
\hline TOTAL & 17.070 .899 .335 \\
\hline
\end{tabular}


TABELA 10. Recursos Transferidos às IES Não-Federais - 1986

\begin{tabular}{l|l|r}
\hline ESPECIFICAÇÃO & FONTE & VALOR \\
\hline \hline \multirow{2}{*}{ AUXÍLIOS } & SESU & 31.000 .000 \\
& FNDE & 141.164 .257 \\
& TOTAL & 172.164 .257 \\
\hline \multirow{2}{*}{ PŃU } & SG & 19.110 .000 \\
& SESU & 17.562 .000 \\
& FNDE & 27.893 .584 \\
\hline TOTAL GERAL & TOTAL & 64.565 .594 \\
\hline
\end{tabular}

Sabemos, entretanto, que os recursos destinados ao sistema federal são insuficientes para a manutenção adequada do ensino. Os salários estão baixos e o montante destinado a custeio é insuficiente.

Para ilustrar, mostramos abaixo o salário de um professor adjunto em 4 de janeiro de 1987 portanto já com os $25 \%$ de aumento concedidos pelo governo.

\section{$\mathrm{C} z \$$}

Salário

Gratificação de Nivel Superior

Dedicação Exclusiva

TOTAL:

17.774

Não vamos aqui discutir o fato de que a maioria dos docentes atinge o nível de adjunto 4 mesmo sem ter qualquer titulação e que um aumento salarial deveria valorizar o mérito e estabelecer salários diferenciados de acordo com a titulação. Vamos supor que seria necessário um aumento de $40 \%$ no total gasto com os salários de docentes e funcionários, para se estabelecer uma remuneração mais adequada com o estabelecimento de uma carreira que valorizasse a titulação acadêmica. Além disso, dever-se-ia aplicar em despesas de custeio, no 
mínimo, um montante da ordem de $20 \%$ do total destinado ao ensino superior. Nessas condições, a preços de 1986, teríamos:

$\mathrm{Cz} \$$ milhões

Despesas de Pessoal

21.364

Custeio + Equipamento

5.341

Amortização

TOTAL:

26.718

Deve-se salientar que a estimativa de uma verba de custeio em torno de $20 \%$ do total (pessoal + custeio) leva em conta dois fatores. Em primeiro lugar o percentual utilizado em universidades de países europeus é em torno de 30\%, porém, nessas universidades a razão aluno/docente é praticamente o dobro da existente nas IES federais. Por outro lado, as IES federais têm recebido, durante vários anos, uma dotação inferior à necessária, pois a verba de custeio tem sido em torno de $10 \%$ do total, e necessitam de uma dotação maior, durante alguns anos, para recompor-se.

Verifica-se que para resolver o problema salarial e adequar a dotação de custeio, o MEC necessita $105 \%$ do valor que lhe cabe da Emenda Calmon. Não há portanto, no momento, condições para um financiamento adequado do sistema de ensino superior, pois isso implicaria em utilizar-se todos os recursos provenientes da Emenda Calmon. 


\section{FICHA CATALOGRÁFICA}

WOLYNEC, E. O financiamento do ensino superior. Revista da Universidade de São Paulo. São Paulo, (5) : 9-19, jun. 1987. 